\title{
Hippocampal Hyperexcitability Underlies Enhanced Fear Memories in TgNTRK3, a Panic Disorder Mouse Model
}

\author{
Mónica Santos, ${ }^{1,2,3 \star}$ Davide D’Amico, ${ }^{1,2,3 *}$ Ornella Spadoni, ${ }^{1,2,3}$ Alejandro Amador-Arjona, ${ }^{4}$ Oliver Stork, ${ }^{5}$ \\ and Mara Dierssen ${ }^{1,2,3}$ \\ ${ }^{1}$ Systems Biology Programme, Centre for Genomic Regulation, E-08003 Barcelona, Spain, ${ }^{2}$ Universitat Pompeu Fabra, E-08003 Barcelona, Spain, ${ }^{3}$ Centro de \\ Investigación Biomédica en Red de Enfermedades Raras, E-08003 Barcelona, Spain, ${ }^{4}$ Department of Stem Cells and Regeneration, Sanford-Burnham \\ Medical Research Institute, La Jolla, California 92037, and ${ }^{5}$ Institute of Biology, Otto-von-Guericke University Magdeburg, and Center for Behavioral Brain \\ Sciences, D39120 Magdeburg, Germany
}

Panic attacks are a hallmark in panic disorder (PAND). During the panic attack, a strong association with the surrounding context is established suggesting that the hippocampus may be critically involved in the pathophysiology of PAND, given its role in contextual processing. We previously showed that variation in the expression of the neurotrophin tyrosine kinase receptor type 3 (NTRK3) in both PAND patients and a transgenic mouse model (TgNTRK3) may have a role in PAND pathophysiology.

Our study examines hippocampal function and activation of the brain fear network in TgNTRK3 mice. TgNTRK3 mice showed increased fear memories accompanied by impaired extinction, congruent with an altered activation pattern of the amygdala- hippocampus - medial prefrontal cortex fear circuit. Moreover, TgNTRK3 mice also showed an unbalanced excitation-to-inhibition ratio in the hippocampal cornu ammonis 3 (CA3)-CA1 subcircuit toward hyperexcitability. The resulting hippocampal hyperexcitability underlies the enhanced fear memories, as supported by the efficacy of tiagabine, a GABA reuptake inhibitor, to rescue fear response.

The fearful phenotype appears to be the result of hippocampal hyperexcitability and aberrant fear circuit activation. We conclude that NTRK3 plays a role in PAND by regulating hippocampus-dependent fear memories.

\section{Introduction}

Human studies have shown that the neurotrophin tyrosine kinase receptor type 3 (NTRK3) gene, encoding the high-affinity tropomyosin receptor kinase $\mathrm{C}(\mathrm{TrkC})$ receptor, may contribute to the genetic susceptibility to psychiatric disorders such as panic disorder (PAND), obsessive-compulsive disorder, or schizophrenia (Gratacòs et al., 2001; Armengol et al., 2002; Alonso et al., 2008; Muiños-Gimeno et al., 2009; Otnaess et al., 2009). Reported NTRK3 genetic variations are predicted to change TrkC mRNA expression levels (Gratacòs et al., 2001; Armengol et al., 2002; Muiños-Gimeno et al., 2009) and alter synaptic plasticity through a change of local trophic support. Indeed, neurotrophins regulate synaptic function and plasticity (for review, see McAllis-

\footnotetext{
Received May 22, 2013; revised July 23, 2013; accepted Aug. 13, 2013.

Author contributions: M.D. designed research; M.S., D.D., 0. Spadoni, A.A.-A., and 0. Stork performed research; M.S., D.D., A.A.-A., and M.D. analyzed data; M.S., D.D., and M.D. wrote the paper.

The laboratory of M.D. is supported by Departament d'Universitats, Recerca i Societat de la Informació (Grups consolidats 09 2009SGR1313). This work was supported by Grants SAF2010-16427, SAF2007-31093-E, and FIS (PI 082038); Marató TV3; the Jerome Lejeune, Koplowitz, and Areces Foundations; and the European Union (LSHG-CT2006-037627; (ureFXS ERare-EU/FIS PS09102673). The Centro de Investigación Biomédica en Red de Enfermedades Raras is an initiative of the Instituto de Salud Carlos III. M.S. was supported by Fundação para a Ciência e Tecnologica (Portugal) with a postdoctoral fellowship, and D.D. was supported by a La Caixa International PhD Programme fellowship.

${ }^{*} M . S$. and D.D. contributed equally to this work.

The authors declare no competing financial interests.

Correspondence should be addressed to Mara Dierssen, Center for Genomic Regulation (CRG)/Barcelona Biomedical Research Park, C/ Dr. Aiguader 88, 08003 Barcelona, Spain. E-mail: mara.dierssen@crg.es.

DOI:10.1523/JNEUROSCI.2161-13.2013

Copyright $\odot 2013$ the authors $\quad 0270-6474 / 13 / 3315259-13 \$ 15.00 / 0$
}

ter et al., 1999; Huang and Reichardt, 2001) and may thus be involved in CNS dysfunction (Minichiello et al., 1999; Sahún et al., 2007; Otnaess et al., 2009; Hong et al., 2011).

PAND is one of the most common anxiety disorders (American Psychiatric Association, 2000; Roy-Byrne et al., 2006) with a lifetime prevalence of 1.1\% to 3.7\% (Goodwin et al., 2005; Kessler et al., 2006; Skapinakis et al., 2011), characterized by the occurrence of panic attacks and disturbances in the fear circuit. In PAND, the context in which panic attack occurs, is a determinant factor in the establishment of the disorder. In this respect, the hippocampus is a key brain structure contributing to the context dependency of fear expression and extinction (Ext; Corcoran et al., 2005; Sierra-Mercado et al., 2011). PAND patients show structural and functional alterations in prefrontal cortex, hippocampus, and amygdala brain regions (Massana et al., 2003a,b; for review, see Charney, 2003) with abnormal frontolimbic activation patterns (Maren and Quirk, 2004; Herry et al., 2008; Sierra-Mercado et al., 2011). TrkC receptor is highly expressed in these brain regions (Ernfors et al., 1992; Krause et al., 2008), and, therefore, even small disturbances in its expression levels might have a strong impact on their function. Several years ago, we validated a transgenic mouse overexpressing human NTRK3 as a model of PAND (Dierssen et al., 2006). TgNTRK3 mice show the following: (1) face validity with increased panic-like reaction and heightened anxiety; (2) construct validity with increased numbers of noradrenergic neurons in the locus ceruleus; and (3) predictive validity as they respond positively to diazepam treatment in the elevated plus maze paradigm (Dierssen et al., 2006). More- 
over, TgNTRK3 mice also show strongly enhanced and sustained hippocampal long-term potentiation (LTP; Sahún et al., 2007).

In this study, we hypothesized that variation in the expression levels of TrkC in fear network brain regions, particularly in the hippocampus, contribute to PAND context-related emotional learning dysfunction. Here, we show that TrkC-overexpressing mice present enhanced fear memories and altered activation of the brain fear circuit. Furthermore, we showed that by targeting the GABAergic system we were able to rescue the enhanced fear memory exhibited by TgNTRK3 mice to normal wild-type (WT) levels.

\section{Materials and Methods}

\section{Animals}

We used young adult (2-4 months old) male TgNTRK3 mice overexpressing the human NTRK3 gene and previously validated as a model of PAND (Dierssen et al., 2006). A double-transgenic line was created by crossing TgNTRK3 with transgenic B6.Cg-Tg(Thy1-YFPH)2Jrs/J mice (The Jackson Laboratory; Feng et al., 2000) named Thy1-YFPH:NTRK3 in which the Thy-1 promoter directs the expression of the yellow fluorescent protein (YFP) to a subpopulation of excitatory neurons. The WT littermates served as controls for all of the experiments. Genotypes were determined by PCR according to protocol established in the laboratory (Dierssen et al., 2006) or, in the case of the fluorescent strains, provided by The Jackson Laboratory. All animal procedures were approved by the local ethics committee, and met the guidelines of the local and European regulations (European Union directive no. 86/609; European Union decree 2001-486).

\section{Pure contextual fear-conditioning paradigm}

The fear-conditioning and fear extinction experimental paradigms were performed in a fear-conditioning apparatus (StartFear, Panlab Harvard Apparatus) and freezing behavior, defined as lack of movement other than breathing for at least $2 \mathrm{~s}$, was automatically recorded using commercial software (FREEZING, Panlab Harvard Apparatus). Freezing response is a reliable measure of conditioned fear in rodents.

Mice were paired an initially neutral context [conditioned stimulus (CS)] with an aversive electric footshock [unconditioned stimulus (US)]. On the first day, animals were placed in the testing chamber for a $3 \mathrm{~min}$ habituation session. Twenty-four hours later, mice were trained in the same chamber in a $5 \mathrm{~min}$ session composed of $2 \mathrm{~min}$ of exploration followed by five US presentations (footshock: $2 \mathrm{~s}, 0.2 \mathrm{~mA}$ ), separated by a variable intertrial interval (ITI; 15-60 s; Fig. 1A); mice remained in the chamber for $30 \mathrm{~s}$ following the last US. Freezing behavior was measured for $15 \mathrm{~s}$ after each shock. Twenty-four hours and 1 week later, mice were tested in the same chamber for contextual fear memory by scoring freezing time in a 2 min session.

\section{Trace fear-conditioning paradigm}

Mice were trained to associate a neutral tone (CS) with an aversive electric footshock (US), separated by a trace (Fig. 1D). On the first day, a 3 min habituation session was performed. Twenty-four hours later, mice were trained in the same chamber in a 7 min session composed of $2 \mathrm{~min}$ of exploration, followed by five CS-US presentations (CS: $10 \mathrm{~s}, 100 \mathrm{~dB}$, $2000 \mathrm{~Hz}$; trace: $18 \mathrm{~s}$; US: $2 \mathrm{~s}, 0.2 \mathrm{~mA}$ ), separated by a variable ITI (from 15 to $60 \mathrm{~s}$ ). Freezing behavior was measured for $18 \mathrm{~s}$ of each trace interval. Twenty-four hours and 1 week after the training session, mice were tested for trace fear memory in the same chamber but with different floor texture, wall color and pattern, odor, and light intensity, without US presentation, by scoring freezing time.

Within-session pure contextual fear extinction, reinstatement, and contextual generalization

Within-session fear extinction was performed $24 \mathrm{~h}$ after pure contextual fear-conditioning training (see above) and consisted of one single session with six trials [extinction session 1 (E1) to E6], each one lasting 2 min and separated from the next by a $1 \mathrm{~h}$ interval. The following day, mice were tested for fear memory extinction in the same context for $2 \mathrm{~min}$. After the extinction test, mice received one US and the reinstatement of the extinguished memory was analyzed by measuring freezing time in a $2 \mathrm{~min}$ session. For contextual generalization assessment, $24 \mathrm{~h}$ after the reinstatement test mice were placed in the same chamber but with different floor texture, wall color and pattern, odor, and light intensity, and freezing was measured for $2 \mathrm{~min}$.

\section{Between-session pure contextual fear extinction}

Mice were first fear conditioned in a pure contextual paradigm (see above) and $24 \mathrm{~h}$ later were subjected to the between-session extinction protocol. For 6 consecutive days (E1-E6), WT and TgNTRK3 mice were presented with the CS without reinforcement by the US in a 2 min session, and freezing time was measured.

\section{Water maze paradigm}

Mice were trained in a water maze paradigm (diameter: pool, $170 \mathrm{~cm}^{2}$; platform, $8 \mathrm{~cm}^{2}$; Vorhees and Williams, 2006), and their movement was detected with a video tracking system (SMART, Panlab Harvard Apparatus). Briefly, animals were subjected to one pretraining, six acquisition, one probe, one cue, and three reversal (platform position is changed $\left.180^{\circ}\right)$ sessions. In every session, mice entered the pool from four different positions and were allowed to search the platform for $60 \mathrm{~s}$. For each session, the latency to reach the platform, the total distance swum, the time spent in periphery, the swimming speed, and the time spent floating were analyzed. The average of the four entry points was used as the final measure. In the removal session, the time spent in each quadrant was used as a measure of visuospatial memory.

\section{Novel object recognition test}

Mice were placed in a $70 \times 70 \mathrm{~cm}^{2}$ open field arena (Panlab Harvard Apparatus), and their behavior was registered. On day 1, behavior of the mice was registered for $5 \mathrm{~min}$, and the following parameters were analyzed: distance traveled, resting time, and time spent in the center of the arena versus the total arena. Ninety minutes later, mice were put back into the arena with one central object for $5 \mathrm{~min}$ (habituation phase). On the following day, two identical objects were placed in the arena, and the time spent exploring each object was registered for $10 \mathrm{~min}$ (familiarization phase). Ninety minutes later, one of the objects of the familiarization phase was changed to a new one, and mice were tested for novel object recognition by measuring the time spent exploring each of the objects for $5 \mathrm{~min}$. The discrimination index was calculated as the time spent exploring the new object minus the time spent exploring the familiar object divided by the total time of exploration.

\section{Peripheral ifenprodil and tiagabine administration}

Animals were submitted to the pure contextual fear-conditioning paradigm (see above) and immediately after training received an intraperitoneal injection of either ifenprodil, a NMDA receptor 2B (NR2B) antagonist ( $1 \mathrm{mg} / \mathrm{kg}$, Sigma) or tiagabine, a GABA reuptake inhibitor (10 $\mathrm{mg} / \mathrm{kg}$, Sigma). Twenty-four hours after drug administration, mice were tested for contextual fear memory (as described above).

\section{Stereotaxic surgery}

Stereotaxic injections were performed in 2- to 3-month-old mice. Briefly, animals were anesthetized with a mixture of medetomidine $(1 \mathrm{mg} / \mathrm{kg}$, i.p.) and ketamine $(75 \mathrm{mg} / \mathrm{kg}$, i.p.), and analgesia was provided by buprenorphine injection $(0.05 \mathrm{mg} / \mathrm{kg}$, s.c.). After complete loss of reflexes, the head was fixed in a stereotaxic apparatus, and, following mouse brain atlas coordinates (Paxinos and Franklin, 2001), two holes in the skull were opened, using a driller, corresponding to the ventral hippocampus, as follows: anteroposterior, $-3.0 \mathrm{~mm}$; mediolateral, $\pm 3.0 \mathrm{~mm}$; dorsoventral, $-2.3 \mathrm{~mm}$. Cannulae (outer diameter, $0.5 \mathrm{~mm}$; inner diameter, $0.25 \mathrm{~mm}$; AISI 304 Unimed) were implanted bilaterally and fixed with dental cement. At the end of the surgical procedure, anesthesia was reversed with atipamezole injection $(2 \mathrm{mg} / \mathrm{kg}$, s.c. $)$.

\section{Intraventral hippocampus tiagabine administration}

After $7 \mathrm{~d}$ of recovery from surgery, mice were trained in the pure contextual fear-conditioning paradigm (see above) and immediately after training were injected with tiagabine $(1 \mu \mathrm{g} / \mathrm{side}$ from a $2 \mathrm{mg} / \mathrm{ml}$ solution; Sigma). The injection was performed in immobilized animals through an internal micro-cannula (outer diameter, $0.2 \mathrm{~mm}$; inner diameter, 0.09 $\mathrm{mm}$; AISI 316L, Unimed), connected with a $15-\mathrm{cm}$-long polyvinyl chlo- 
A

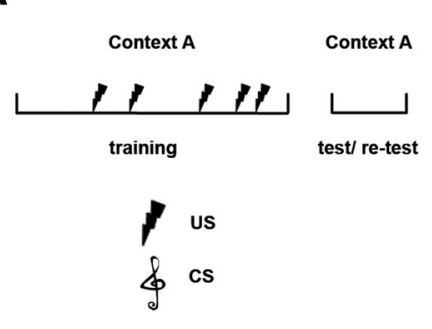

D

G

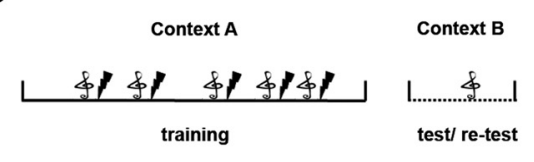

\section{Contextual fear memory}

B

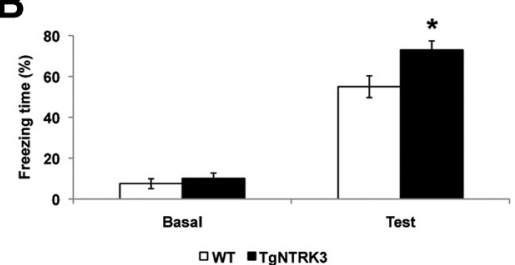

Trace fear memory

E

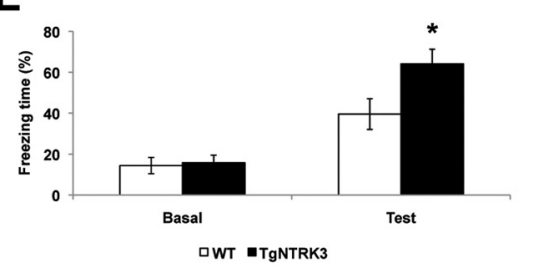

C

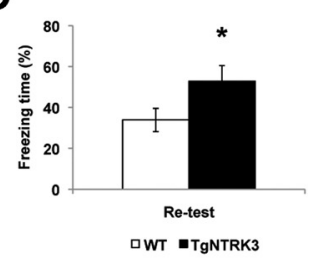

$\mathbf{F}$

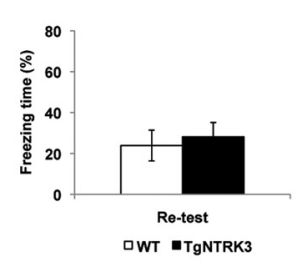

Extinction of fear memory

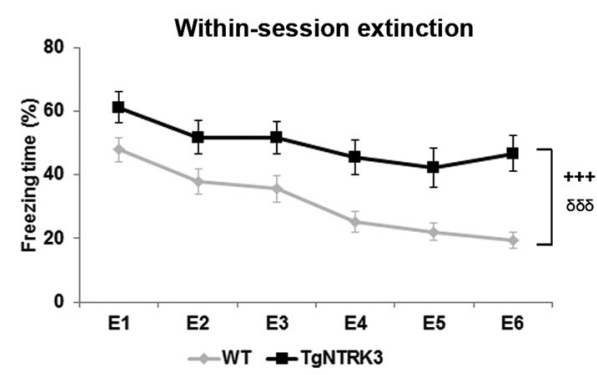

I

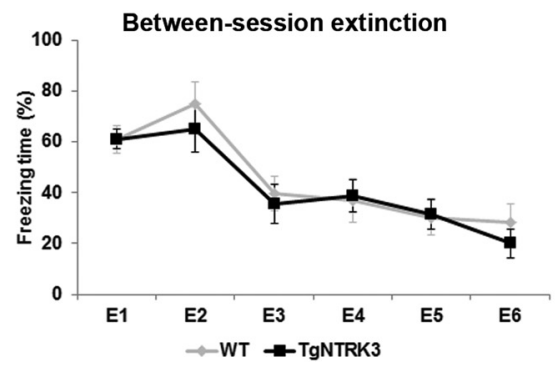

$\mathrm{H}$

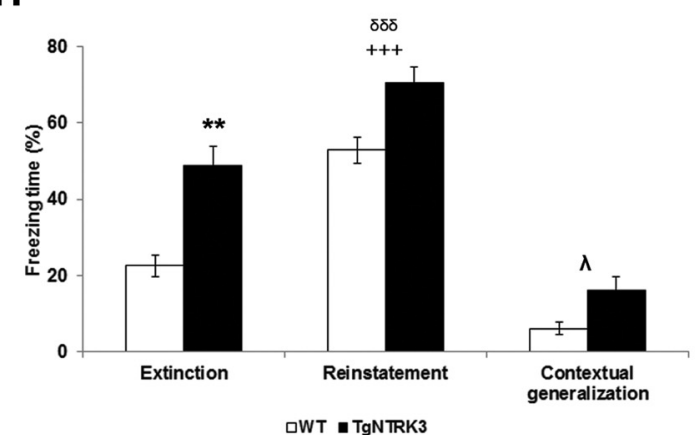

Figure 1. Increased hippocampus-dependent fear memory and resistance to extinction in TgNTRK3 mouse model of panic disorder. $\boldsymbol{A}$, Schematic representation of pure contextual fear-conditioning paradigm. $B, C$, Twenty-four hours (test) and 1 week (retest) after fear-conditioning training, contextual fear memory is higher in TgNTRK3 compared with WT mice (Student's $t$ test; $n=19$ and $n=22$, respectively). $\boldsymbol{D}$, Schematic representation of trace fear-conditioning paradigm. $\boldsymbol{E}, \boldsymbol{F}$, Twenty-four hours, but not 1 week, after trace fear-conditioning training, trace fear memory is higher in TgNTRK3 compared with WT mice (Student'st test; $n=21$ and $n=19$, respectively). $\mathbf{G}, \mathbf{I}$, After pure contextual fear conditioning, mice were submitted to different fear extinction paradigms. When tested in the within-session fear extinction paradigm, TgNTRK3 mice showed impairment in extinction acquisition (repeated-measures two-way ANOVA; WT, $n=26 ;$ TgNTRK3, $n=22 ; \boldsymbol{G}$ ) and extinction memory (Student's t test; WT, $n=21$; TgNTRK3, $n=19 ; \boldsymbol{H})$ compared with WT. Presentation of the US after extinction resulted in reinstatement of fear both in WT and TgNTRK3 mice ( $n=16$ and $n=14$, respectively), but at higher levels in the transgenic animals (two-way ANOVA, reinstatement vs extinction). This is not due to a generalization offear since when tested in a new context, freezing time is reduced in both genotypes (WT, $n=16$; TgNTRK3, $n=14$ ) compared with extinction freezing levels (two-way ANOVA, contextual generalization vs extinction). $I$, In the between-session fear extinction paradigm, no differences in fear extinction were found between genotypes (repeated-measures two-way ANOVA; WT, $n=13$; TgNTRK3, $n=14$ ). Student's $t$ test: ${ }^{*} p<0.05$; ${ }^{* *} p<0.01 ;$ Trial/day/test effect: ${ }^{+++} p<0.001$. Genotype effect: ${ }^{\delta \delta \delta} p<0.001$. Genotype $\times$ test interaction: ${ }^{\lambda} p=0.083$.

ride tube (inner diameter, $0.25 \mathrm{~mm}$; F117952, Gilson) to a $5 \mu$ Hamilton syringe. The internal cannula exited $1 \mathrm{~mm}$ from the implanted cannula, and the injection was performed with a rate of $250 \mathrm{nl} / \mathrm{min}$. After the injection, animals were placed in their home cage, and $24 \mathrm{~h}$ later they were tested for contextual fear memory.

\section{Protein extraction}

Mice were anesthetized (mixture of $1.0 \mathrm{mg} / \mathrm{kg}$ medetomidine and 0.1 $\mathrm{mg} / \mathrm{kg}$ ketamine) and intracardially perfused with PBS, pH 7.6. Brains were removed, and hippocampi were dissected and quickly frozen in dry ice. Tissue was homogenized with a 20 gauge needle in $100 \mu \mathrm{l}$ of lysis buffer (137 mm NaCl, $20 \mathrm{~mm}$ Tris- $\mathrm{HCl}, \mathrm{pH} 8.0,1 \% \mathrm{NP} 40$, and $10 \%$ glycerol) with protease ( 1 complete pill and $1 \mathrm{~mm}$ phenylmethylsulfonyl fluoride) and phosphatase ( $1 \mathrm{~mm} \mathrm{NaF}$ and $1 \mathrm{~mm} \mathrm{Na}_{3} \mathrm{VO}_{4}$ ) inhibitors. After homogenization, samples were vortexed and kept in ice for $3 \times 5 \mathrm{~min}$. Finally, samples were centrifuged for $30 \mathrm{~min}$, at $13,200 \mathrm{rpm}$, at $4^{\circ} \mathrm{C}$, and the supernatant was collected and stored at $-80^{\circ} \mathrm{C}$. Protein quantification was performed using the BCA protein assay kit (Thermo Scientific). 
Western blot of glutamic acid decarboxylase 65/67 and vesicular glutamate transporter

Fifty micrograms of protein were loaded in $12 \%$ polyacrylamide gel, separated by electrophoresis and transferred to nitrocellulose membrane. After blocking ( $5 \%$ milk) membranes were incubated overnight at $4^{\circ} \mathrm{C}$ with the respective primary antibodies in $0.1 \%$ Tris-buffered saline/ 2.5\% milk: rabbit anti-glutamic acid decarboxylase 65/67 (GAD65/67; 1:8000; Millipore), mouse anti-vesicular glutamate transporter 1 (VGLUT1; 1:1000; Synaptic Systems), and rabbit anti-ACTIN (1:5000; Sigma). Adequate secondary antibodies polyclonal goat anti-rabbit Ig/ horseradish peroxidase (HRP) and polyclonal rabbit anti-mouse Ig/HRP (Dako) were used. Detection was performed with enhanced chemiluminescence Western blotting detection reagents (GE Healthcare) developed with the Fujifilm LAS 3000 imaging system (R\&D Systems), and bands were quantified (MultiGauge version 3.0 software).

\section{Immunofluorescence}

Animals were anesthetized (mixture of $0.1 \mathrm{mg} / \mathrm{kg}$ ketamine and $1 \mathrm{mg} / \mathrm{kg}$ medetomidine) and intracardially perfused with PBS (0.01 M), $\mathrm{pH} 7.6$, followed by $4 \%$ paraformaldehyde (PFA). Brains were removed and kept at $4^{\circ} \mathrm{C}$ in $4 \%$ PFA for $24 \mathrm{~h}$ for postfixation and then were transferred to a solution of $30 \%$ sucrose in PBS for $2 \mathrm{~d}$. A series of coronal sections $(40 \mu \mathrm{m})$ was obtained using a vibratome (VT1000S; Leica Microsystems) and stored at $-20^{\circ} \mathrm{C}$ in a cryoprotector (30\% ethylenoglycol, $30 \%$ glycerol, $40 \%$ PBS).

Free-floating brain sections were permeabilized with $0.3 \%$ Triton $\mathrm{X}-100$ in PBS for $30 \mathrm{~min}$ at room temperature (RT) and blocked with 3\% bovine serum albumin/0.3\% Triton X-100 in PBS for $1 \mathrm{~h}$ at RT. Subsequently, sections were incubated overnight at $4^{\circ} \mathrm{C}$ with the following primary antibodies: mouse anti-VGLUT1 monoclonal antibody (1:200; clone 317G6, Synaptic Systems); guinea pig anti-vesicular GABA transporter (VGAT) polyclonal antibody (1:200; cytoplasmatic domain, Synaptic Systems); rabbit anti-postsynaptic density 95 (PSD-95) polyclonal antibody (1:250; Abcam); and rabbit anti-c-Fos polyclonal antibody (1: 500; H-125, Santa Cruz Biotechnology). The following secondary antibodies were used: Alexa Fluor 488 goat anti-mouse IgG, Alexa Fluor 555 goat anti-guinea pig IgG, and Alexa Fluor 594 goat anti-rabbit IgG (1: 1000, Life Technologies) for $1 \mathrm{~h}$ at RT, protected from light. Finally, sections were mounted and nuclei were stained on glass slides with Vectashield with DAPI (Vector Laboratories).

VGLUT1/VGAT puncta analysis. Pictures were captured in the stratum radiatum (srad) of cornu ammonis 1 (CA1) and CA3 hippocampal subfields using a confocal microscope with a $63 \times$ objective and $5 \times$ magnification (TCS SPE, Leica Microsystems). For each region, all pictures were captured with identical confocal settings for laser power, gain, and offset levels. Images were imported into IMAGEJ 1.42l (Macbiophotonics), and in each image the negative control background intensity was subtracted for each channel, and converted into binary data and threshold to outline immunopositive puncta. The number and size of VGLUT1 and VGAT puncta per field were quantified using the "analyze particle" function of the software.

VGLUT1/PSD-95 puncta colocalization. Image acquisition and puncta quantification were obtained as described above. For colocalization analysis, threshold images of each channel were superimposed using the Colocalization Highlighter plugin of IMAGEJ 1.421 software, and quantified with the analyze particle function. The average number of VGLUT1/ PSD-95 double-positive puncta per genotype was reported normalized for WT values.

Thy1-YFP/c-Fos analysis. Analysis of Thy1-YFP/c-Fos double-positive neurons was performed in the hippocampus from each animal. Images were captured using a confocal microscope (TCS SP5, Leica Microsystems) at $40 \times$ magnification. For each area of interest, a $10 \mu \mathrm{m} z$-stack was captured including the two consecutive pictures in the central part of the CA1 stratum pyramidale (CAlpy) and one in the central part of CA3py of the hippocampus. A $z$-maximum projection of each stack was performed by IMAGEJ 1.421 software, the area of interest was drawn, and the number of double-positive neurons was quantified manually. The mean number of positive neurons per area is reported.

\section{c-Fos immunohistochemistry}

Brain sections were incubated with $10 \% \mathrm{MeOH}, 3 \% \mathrm{H}_{2} \mathrm{O}_{2}$ in $0.01 \mathrm{M}$ PBS, pH 7.6, for 30 min at RT to block endogenous peroxides and was permeabilized with $0.2 \%$ Triton X-100 in PBS $(2 \times 5 \mathrm{~min})$ at RT. Unspecific binding was blocked with $10 \%$ fetal bovine serum and $0.2 \%$ Triton X-100 in PBS for $1 \mathrm{~h}$ at RT. Subsequently, sections were incubated overnight at $4^{\circ} \mathrm{C}$ with rabbit anti-c-Fos polyclonal primary antibody (1:1000; H-125, Santa Cruz Biotechnology) followed by incubation with biotinylated anti-rabbit secondary antibody (1:300; Vector Laboratories) for $1 \mathrm{~h}$ at RT. The staining was developed using the avidin-biotin-peroxidase complex (Vectastain ABC kit, Vector Laboratories) and 3,3-diaminobenzidine as a chromogen. c-Fospositive neurons were counted manually using an optical microscope (BX51, Olympus) and a CAST grid stereology system (Olympus) in the medial prefrontal cortex [MPFC; prelimbic (PL) and infralimbic (IL) areas], in the CA1py and CA3py layers of hippocampus, and in different nuclei of the amygdala (central, basal, lateral, and the intercalated cell clusters). The mean number of c-Fos-positive neurons per area is reported.

\section{Statistical analysis}

A Student's $t$ test for independent samples was used to compare data when two independent groups were considered. Two-way ANOVA was used to compare data when two factors were considered (Bonferroni post hoc test). Repeated-measures two-way ANOVA was used to compare data when two factors were considered and repeated measures were available (Bonferroni post hoc). Statistical significance was set at $p \leq 0.05$, and the results are expressed as the mean \pm SEM.

\section{Results}

\section{Enhanced hippocampus-dependent fear memories in the TgNTRK3 mouse model}

In a pure contextual fear-conditioning paradigm (Fig. 1A), no differences were found between genotypes during the training session (data not shown). However, in the test session TgNTRK3 mice showed a significantly higher freezing time compared with WT mice (Fig. $1 B ; t_{(39)}=-2.6, p=0.014$ ). This increased fear response was maintained in the retest session (Fig. $1 C ; t_{(34.4)}=$ $-2.0, p=0.055)$.

In the trace fear-conditioning paradigm (Fig. 1D), again TgNTRK3 and WT mice learned the CS-US association equally during the training session (data not shown). Strikingly, in the trace fear-conditioning test session, hippocampus-dependent TgNTRK3 mice also showed higher freezing time than WT mice (Bangasser et al., 2006; Fig. $1 E$; $t_{(38)}=-2.4, p=0.023$ ). Both in the retest session of trace fear conditioning (Fig. $1 F ; t_{(38)}=-0.4$, $p=0.680$ ) and in the delay fear-conditioning paradigm (data not shown), two tasks that are less hippocampus dependent (Bangasser et al., 2006; Quinn et al., 2008), no differences were found. These data point to a critical involvement of the hippocampus in the performance of TgNTRK3 mice in fear paradigms.

Next, pure contextual fear-conditioned TgNTRK3 and WT animals were subjected to different fear extinction paradigms. In the within-session extinction paradigm, TgNTRK3 mice showed impaired extinction of acquired fear (Fig. 1G; genotype effect: $F_{(1,27)}=23.2, p=5.0 \mathrm{E}-05$; trial effect: $F_{(5,135)}=11.2, p=5.2 \mathrm{E}-$ $09)$. In the test session, TgNTRK3 mice showed significantly higher freezing behavior compared with WT mice, suggesting that TgNTRK3 mice have impaired extinction memory (Fig. $1 H$; $\left.t_{(27.4)}=-3.7 ; p=0.001\right)$. In the reinstatement session, both genotypes increased the percentage of time spent freezing compared with the extinction session (Fig. $1 H$; test effect: $F_{(1,66)}=$ 25.5, $p=3.8 \mathrm{E}-06)$ with higher freezing response in TgNTRK3 mice (genotype effect: $F_{(1,66)}=18.1, p=6.9 \mathrm{E}-05$ ). The freezing behavior was not generalized to a new context in either genotype (Fig. $1 H$; genotype $\times$ test effect: $F_{(1,66)}=3.1 ; p=0.083$ ). Post hoc 

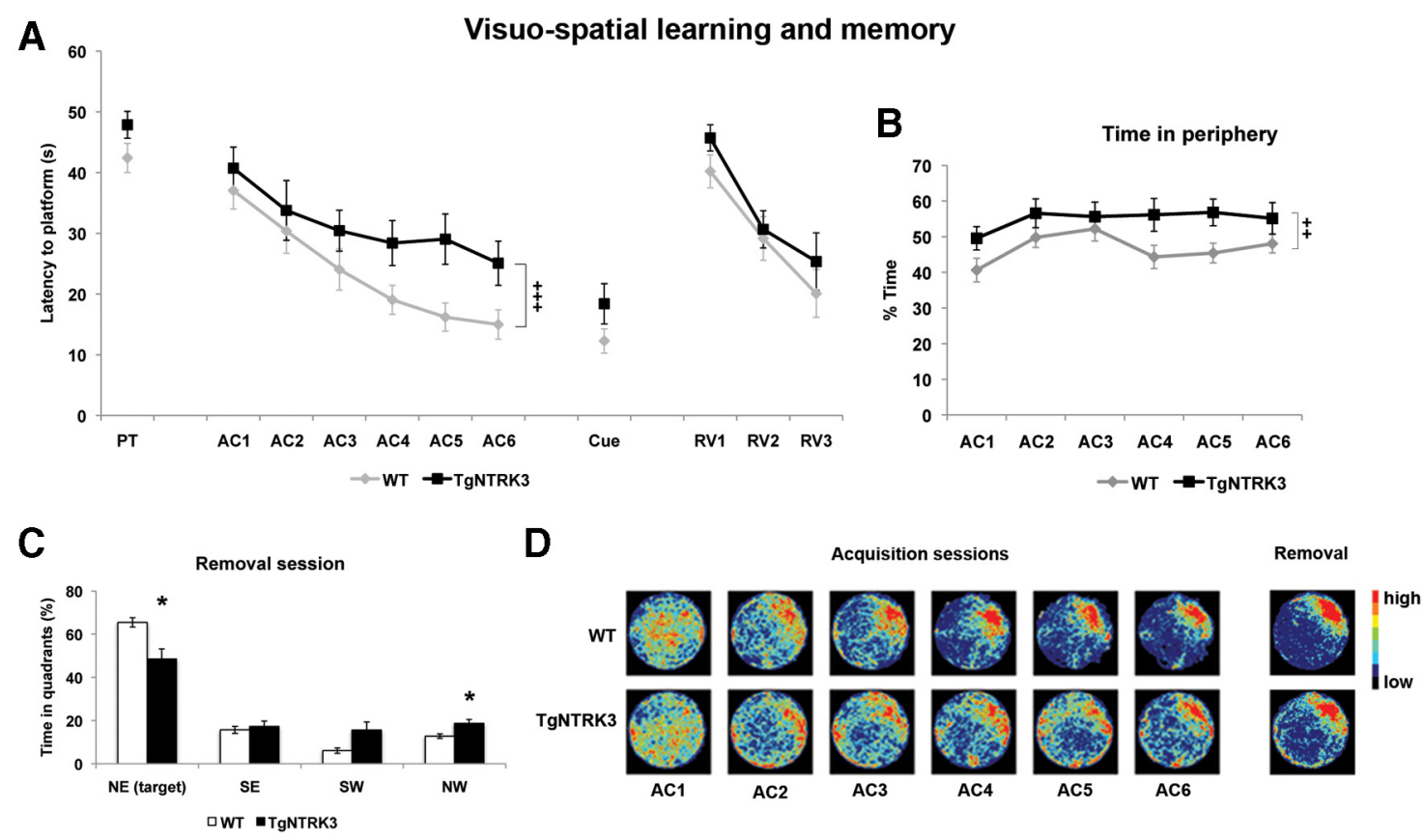

Figure 2. Impaired visuospatial learning and memory of TgNTRK3 mice in a water maze paradigm. A, Escape latency of WT and TgNTRK3 mice $(n=18$ and $n=19$, respectively) was similar in the pretraining and cue (Student's $t$ test) and reversal (repeated-measures two-way ANOVA) sessions. During the acquisition sessions, although both genotypes learned the platform position, TgNTRK3 mice showed worse performance (repeated-measures two-way ANOVA). B, TgNTRK3 mice showed a higher percentage of time spent swimming in periphery (repeated-measures two-way ANOVA) during the acquisition sessions. C, In the removal session, WT and TgNTRK3 mice showed preference for the target quadrant (repeated-measures two-way ANOVA), but TgNTRK3 mice showed a less focused searching strategy, with increased an percentage of time spent swimming in the adjacent quadrants. $D$, Color-coded map representing the spatial distribution of WT and TgNTRK3 mice activity in the acquisition and removal sessions. PT, pretraining; AC1-AC6, acquisition sessions 1-6; RV1-RV3, reversal sessions 1-3; NE, northeast; $\mathrm{SE}$, southeast; SW, southwest; NW, northwest. Post hoc comparisons: ${ }^{*} p<0.05$. Day effect: ${ }^{++} p<0.001{ }^{++} p<0.01$.

Bonferroni comparisons showed no significant differences between genotypes in contextual generalization as opposed to extinction (contextual generalization: WT vs TgNTRK3, $p=0.15$; extinction: WT vs TgNTRK3, $p=4.4 \mathrm{E}-05)$. In the betweensession extinction paradigm, analysis of the extinction curves revealed a day effect with no differences between genotypes (Fig. 1I; day effect: $F_{(5,60)}=18.7, p=3.9 \mathrm{E}-11$; genotype effect: $F_{(1,12)}=$ $0.1, p=0.786)$. These results suggest that the schedule used for the extinction of fear memory defines its efficiency in TgNTRK3 mice.

\section{Impaired spatial memory in the $\operatorname{TgNTRK3}$ mice}

In the water maze paradigm, $\operatorname{TgNTRK} 3$ mice showed learning and memory impairments (Fig. $2 A-D$ ). In the pretraining session, TgNTRK3 mice showed a slower swimming speed (TgNTRK3 mice, $21.8 \mathrm{~cm} / \mathrm{s}$; WT mice, $24.0 \mathrm{~cm} / \mathrm{s} ; t_{(41)}=2.5$, $p=0.017$ ), which did not affect the latency (Fig. $2 A ; t_{(41)}=-1.7$; $p=0.093$ ) or the distance swum (data not shown) to reach the platform, suggesting that motor impairments would not interfere with the visuospatial learning.

No differences for genotype or session were found in the swimming speed or floating behavior along the acquisition, removal, or cue sessions (data not shown). Analysis of the acquisition curves revealed a statistically significant effect of day (Fig. $\left.2 A, D ; F_{(5,100)}=22.1 ; p=4.0 \mathrm{E}-09\right)$ and a trend toward a main effect for genotype $\left(F_{(1,20)}=3.3, p=0.084\right)$ on the escape latencies, indicating that $\operatorname{TgNTRK3}$ and WT mice were able to learn but to different levels. The same pattern was found when the distance swum was analyzed (data not shown). This slight learning impairment may in part be due to the thigmotaxic searching strategy used by TgNTRK3 mice (Fig. $2 B, D$; session effect: $F_{(5,100)}=3.7, p=$ 0.004; genotype effect: $\left.F_{(1,20)}=3.5, p=0.075\right)$.
In the removal session, a significant genotype $\times$ quadrant interaction was found (Fig. $2 C, D ; F_{(3,60)}=5.8 ; p=0.012$ ). Both genotypes showed preference for the target quadrant (post hoc Bonferroni correction, $p<0.001$ ), but TgNTRK3 mice showed a less focused searching strategy, spending less time in the target $(p=0.012)$ and more time in the adjacent quadrant $(p=0.008)$ than WT mice. In the cue session, no differences were found between genotypes in the latency to reach the cued platform (Fig. $2 A$ ) or the percentage of time spent in periphery (data not shown). Analysis of the reversal learning session revealed a significant session effect in the latency to reach the platform (Fig. $2 A ; F_{(2,32)}=30.0 ; p=1.3 \mathrm{E}-05$ ) and distance swum (data not shown), indicating that both genotypes learned the new position of the platform. As in the acquisition, TgNTRK3 mice showed a more thigmotaxic behavior (data not shown). TgNTRK3 mice swam at a lower speed than WT mice (WT, $24.4 \mathrm{~cm} / \mathrm{s}$; TgNTRK3, $\left.19.1 \mathrm{~cm} / \mathrm{s} ; F_{(1,16)}=5.4, p=0.034\right)$ with no differences in floating behavior (data not shown).

Overall, the impaired performance in the probe session (removal) and a trend toward impairment in the acquisition sessions by TgNTRK3 mice suggest that memory cognitive domain is mainly affected rather than learning, as was found for the fearconditioning paradigms.

\section{Novelty recognition is not altered in the TgNTRK3 mice}

No differences were found between genotypes during free exploration of the open field (data not shown), in accordance with our previous report (Dierssen et al., 2006), or in the exploration time for the central object during the habituation session (data not shown). In the familiarization phase, WT and $\operatorname{TgNTRK} 3$ mice equally explored the two objects (Fig. $3 A$; object effect: $F_{(1,17)}=$ $2.4, p=0.14$; genotype effect: $\left.F_{(1,17)}=1.1, p=0.31\right)$, and in the 
A

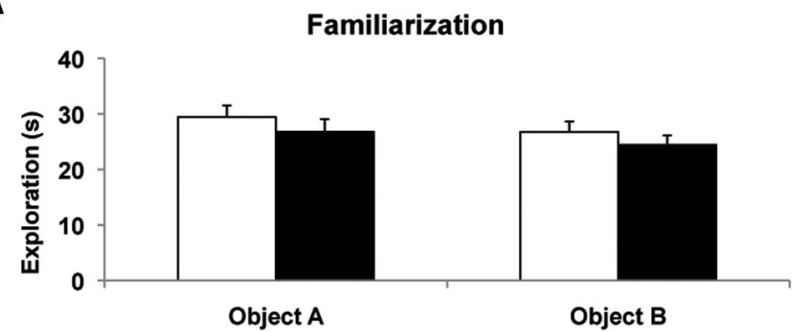

B

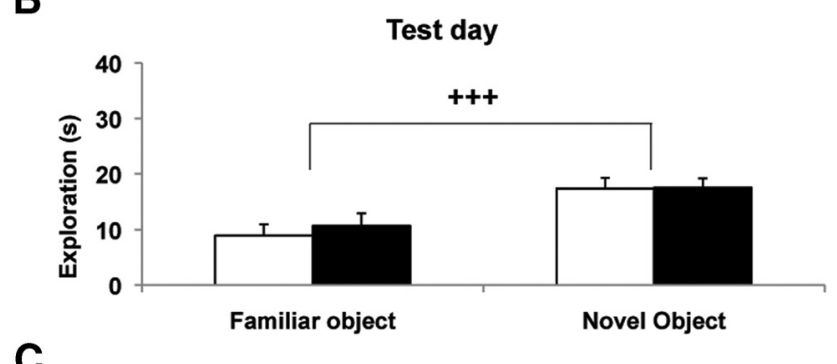

C

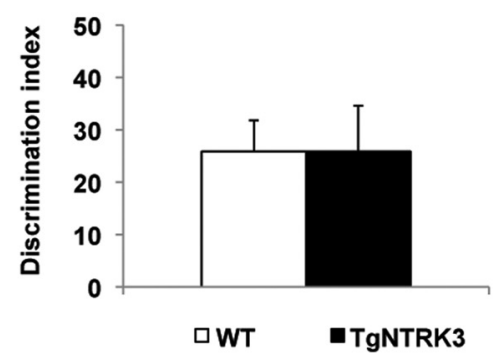

Figure 3. Intact novelty recognition in TgNTRK3 mice. $\boldsymbol{A}$, In the familiarization session, WT and TgNTRK3 mice ( $n=18$ and $n=19$, respectively) showed equal levels of exploration of both objects (repeated-measures two-way ANOVA). B, C, In the test session, both genotypes spent more time exploring the novel object compared with the familiar object (repeated-measures two-way ANOVA) with a similar discrimination index. Novel object effect: ${ }^{+++} p<0.001$.

test session WT and TgNTRK3 mice spent equally more time exploring the novel object (Fig. $3 B, C$; object effect: $F_{(1,17)}=23.9$, $p=0.0001$; genotype effect: $\left.F_{(1,17)}=1.1, p=0.30\right)$.

TgNTRK3 mice show a differential neuronal activation pattern in naive, fear-conditioned, and fear extinction conditions

To analyze how the fear circuit is activated in TgNTRK3 compared with WT mice, we quantified the number of c-Fos-positive cells in the hippocampus (specifically in the CA1py and CA3py subfields, where cell bodies of pyramidal neurons are located), in several amygdala nuclei (basolateral, central and intercalated cell clusters), and in mPFC (focusing on prelimbic and infralimbic regions that modulate fear responses) brain regions upon pure contextual fear conditioning and extinction compared with the naive state.

\section{Neuronal activation pattern in naive and \\ fear-conditioned mice}

In the hippocampus, we quantified the number of c-Fospositive cells.

One hour after fear-conditioning training, we observed increased activation of both dorsal (data not shown) and ventral hippocampus CA1py and CA3py layers compared with the naive condition in both genotypes [Fig. 4A, $B$; fear-conditioning (FC) training effect: ventral CA1py: $F_{(1,18)}=25.6, p=8.2 \mathrm{E}-05$; CA3py:
$\left.F_{(1,18)}=28.9, p=4.2 \mathrm{E}-05\right]$. However, the ventral hippocampus of TgNTRK3 mice showed a significant genotype $\times$ FC interaction in ventral CAlpy layer $\left(F_{(1,18)}=4.5, p=0.048\right)$. In this subfield, fear conditioning activates at much higher levels in TgNTRK3 neurons (WT-naive vs WT-FC, $p=0.052$; TgNTRK3naive vs TgNTRK3-FC, $p=7.9 \mathrm{E}-05$; TgNTRK3-FC vs WT-FC, $p=0.013)$. Also, a higher number of c-Fos-positive cells in CA3py layer of TgNTRK3 mice compared with WT mice was found (genotype effect: $F_{(1,18)}=6.1, p=0.024$ ). The increased activation of ventral CA1py and CA3py layers in TgNTRK3 mice could contribute to the increased contextual fear memory observed in the transgenic animals.

We also analyzed the activation of the amygdala, the core brain region in the fear circuit. In the centrolateral nucleus of amygdala $(\mathrm{CeL})$, the number of c-Fos-positive cells in both WT and TgNTRK3 mice was reduced after fear conditioning (Fig. $4 A, C$; FC effect: $\left.F_{(1,17)}=9.7, p=0.006\right)$. In the centromedial nucleus of amygdala (CeM), which sends projections to regions that finally orchestrate the fear response, a significant genotype $X$ FC interaction was detected (Fig. $4 A, C ; F_{(1,17)}=5.3 ; p=0.034$ ), and post hoc comparisons revealed that in naive conditions the CeM of TgNTRK3 mice was more activated than in WT mice (WT-naive vs TgNTRK3-naïve, $p=0.003$ ). After fear conditioning, neuronal activation was significantly increased in TgNTRK3 (TgNTRK3-naive vs TgNTRK3-FC, $p=4.0$ E-04) but not in WT mice (WT-naive vs WT-FC, $p=0.329$ ), with a significant genotype difference (WT-FC vs TgNTRK3-FC, $p=2.2 \mathrm{E}-06$ ). In addition, the ventral hippocampal and mPFC inputs mostly impinge on basolateral amygdala (BLA) and intercalated nuclei (ITC) to regulate fear responses. We did not find any differences in the number of c-Fos-positive cells in the lateral (LA) and basal (BA) subdivisions of the BLA between genotypes, both in naive and fear-conditioning states (Fig. $4 C$; LA: genotype effect, $F_{(1,17)}=$ $0.81, p=0.38$; FC effect, $F_{(1,17)}=0.99, p=0.34$; genotype $\times$ FC interaction, $F_{(1,17)}=0.66, p=0.43$; BA: genotype effect, $F_{(1,17)}=$ $1.53, p=0.23$; FC effect, $F_{(1,17)}=0.09, p=0.76$; genotype $\times$ FC interaction, $\left.F_{(1,17)}=0.61, p=0.44\right)$. Interestingly, in the lateral ITC (IITC) naive TgNTRK3 animals showed an increased number of c-Fos-positive neurons compared with their respective WT group, and fear conditioning reduced the number of activated cells only in TgNTRK3 animals (Fig. $4 C$; genotype $\times$ FC interaction: $F_{(1,17)}=6.0, p=0.025$; Bonferroni post hoc test: WT-naive vs TgNTRK3-naïve, $p=0.023$; TgNTRK3-naive vs TgNTRK3FC, $p=0.039$ ). In the medial ITC (mITC), we observed that upon fear conditioning a differential activation pattern is produced in WT and TgNTRK3 mice. Fear conditioning increased the number of c-Fos-positive cells in WT but not in TgNTRK3 mice (Fig. $4 C$; genotype $\times$ FC interaction: $F_{(1,17)}=7.4, p=0.014$; Bonferroni post hoc test: WT-naive vs WT-FC, $p=0.049$; TgNTRK3-naive vs TgNTRK3-FC, $p=0.10$; WT-FC vs TgNTRK3FC, $p=0.028$ ).

In the $\mathrm{mPFC}$, which is thought to play an important role in inhibiting the amygdala and blocking fear responses, fear conditioning did not change the number of activated neurons in either WT or TgNTRK3 mice compared with the naive condition in the PL area (Fig. $4 A, D ; F_{(1,18)}=3.4 ; p=0.081$ ). However, in the IL region a significant genotype $\times$ FC effect is revealed (Fig. $4 A, D$; $\left.F_{(1,18)}=4.5, p=0.048\right)$, and post hoc comparisons showed that fear conditioning reduced neuronal activation in TgNTRK3 but not in WT mice (TgNTRK3-naive vs TgNTRK3-FC, $p=1.2 \mathrm{E}-04$; WT-naive vs WT-FC, $p=0.08$ ). 
A
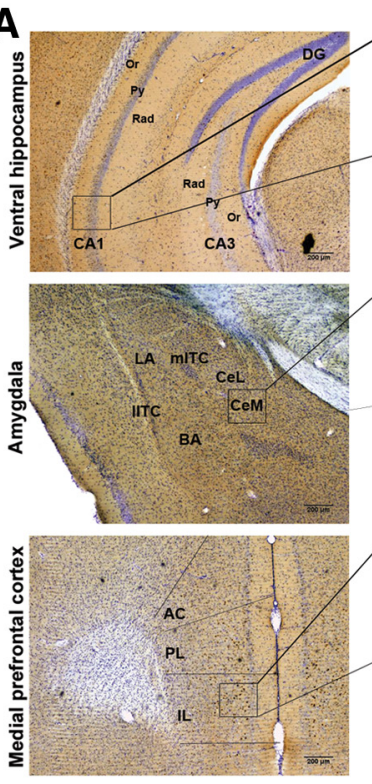

B

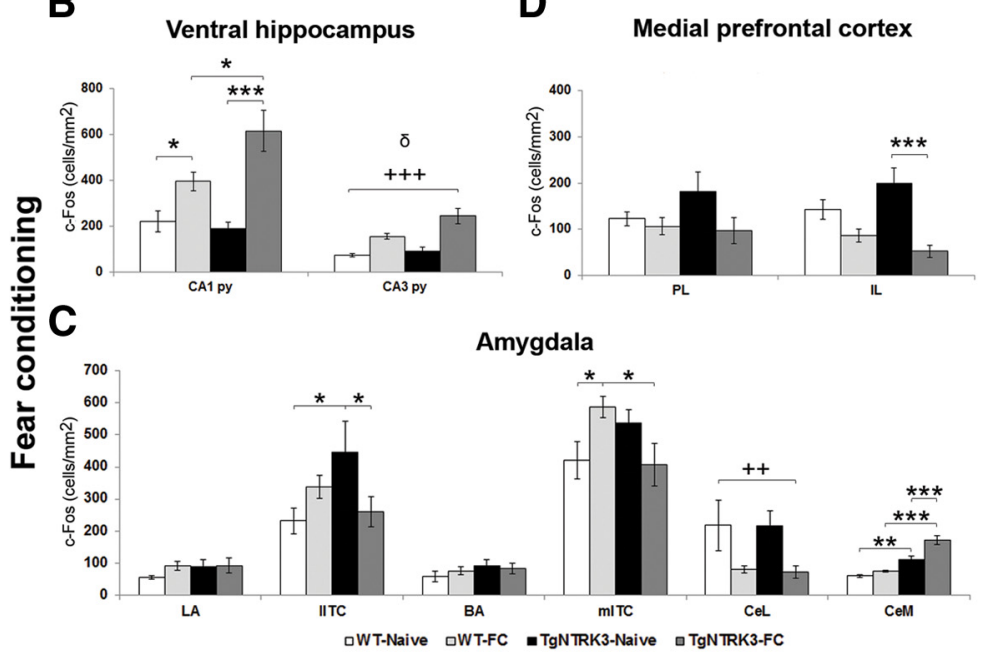

\section{E}

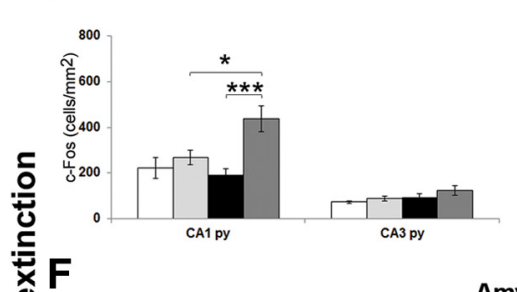

G Medial prefrontal cortex

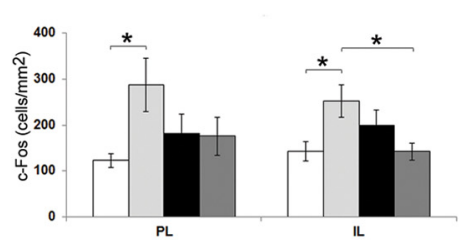

$x$

离

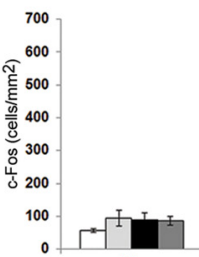

LA

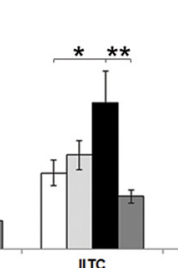

BA

\section{Amygdala}

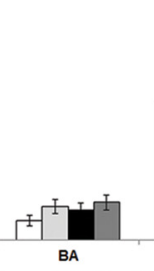

mic

GTgNTRK3-Ext

Figure 4. Altered neuronal activation pattern of the TgNTRK3 amygdala-hippocampus-mPFC fear circuit in naive, fearconditioned and fear-extinguished states. $A$, Representative photomicrographs of c-Fos immunohistochemistry of WT and TgNTRK3 ventral hippocampus, amygdale, and $\mathrm{mPFC}$ brain regions in naive, $\mathrm{FC}$, and Ext states. $\boldsymbol{B}-\boldsymbol{D}$, Number of $\mathrm{c}-\mathrm{Fos}$-positive cells in naive $(n=5$ per genotype) and FC training groups ( $n=6$ per genotype) in ventral hippocampus $(\boldsymbol{B})$, amygdala $(\boldsymbol{C})$, and $\mathrm{mPFC}(\boldsymbol{D})$ brain regions. In brief, a higher neuronal activation was found in ventral hippocampus CA1py and CeM in TgNTRK3 compared with WT mice. In contrast, in the IITC and mITC of the amygdala and in the IL region of the MPFC a marked reduction of c-Fos expression
Neuronal activation after extinction of conditioned fear

In the ventral hippocampus, fear extinction increased CAlpy neuronal activation in TgNTRK3 mice, but not in WT mice, compared with the naive condition (Fig. $4 A$,E; genotype $\times$ fear Ext: $F_{(1,16)}=5.7, p=0.03$; Bonferroni post hoc test: TgNTRK3-naive vs TgNTRK3-Ext, $p=7.1 \mathrm{E}-04$; WT-Ext vs TgNTRK3-Ext, $p=0.012)$. No differences were found in ventral CA3py layer (genotype effect: $F_{(1,16)}=3.2, p=0.094$; Ext effect: $F_{(1,16)}=2.4, p=0.14$; genotype $\times$ Ext interaction: $\left.F_{(1,16)}=0.22, p=0.65\right)$. Again, no significant differences were observed in the dorsal CA1py and CA3py hippocampal subfields (data not shown).

In the amygdala, $1 \mathrm{~h}$ after fear extinction training, a significant Ext effect was found in the CeL nucleus (Fig. 4A,F; $\left.F_{(1,16)}=7.5, p=0.015\right)$, with extinction training reducing c-Fos numbers in both genotypes. Quantification of c-Fosimmunopositive nuclei revealed increased numbers of c-Fos-positive cells in the CeM of TgNTRK 3 compared with WT mice (Fig. $4 A, F$; genotype $\times$ Ext interaction: $F_{(1,16)}=$ $6.4, p=0.022$ ), with a higher number of c-Fos-positive cells detected in TgNTRK3 mice both in the naive condition and after the extinction paradigm (WT-naive vs TgNTRK3-naive, $p=0.001$; WT-Ext vs TgNTRK3-Ext, $p=1.5 \mathrm{E}-06)$. In both the LA and BA subdivisions of the BLA nucleus, no differences were found in the number of c-Fos-positive cells between genotypes, in naive and fear extinction states (Fig. 4F; LA: genotype effect, $F_{(1,16)}=0.43, p=0.52$; Ext effect, $F_{(1,16)}=0.87 p=0.37$; genotype $\times$ Ext interaction, $F_{(1,16)}=1.43, p=0.25$; BA: genotype effect, $F_{(1,16)}=1.29, p=0.27$; Ext effect, $F_{(1,16)}=2.48, p=0.14$; genotype $\times$ Ext interaction, $\left.F_{(1,16)}=0.27, p=0.61\right)$. In the IITC, naive TgNTRK3 animals presented an increased number of c-Fos-

\section{$\leftarrow$}

is observed after FC in TgNTRK3 mice. $E-G$, Number of c-Fospositive cells in naive ( $n=5$ per genotype) and Ext groups ( $n=5$ per genotype) in ventral hippocampus $(\boldsymbol{E})$, amygdala $(\boldsymbol{F})$, and $\operatorname{mPFC}(\boldsymbol{G})$ brain regions. Briefly, TgNTRK3 mice showed higher c-Fos expression in ventral hippocampus CA1py after fear extinction compared with other groups. In the CeM nucleus of the amygdala, the number of c-Fos cells was already higher in naive TgNTRK3 compared with WT mice, and fear extinction did not reduce this number in transgenic animals. In both the IITC and the mITC of TgNTRK3 mice, fear extinction reduced the number of c-Fos neurons, without any change in WT mice. Moreover, fear extinction activated PL and IL regions in WT but not in TgNTRK3 mice. Or, Stratum oriens; DG, dentate gyrus; $A C$, anterior cingulum. Genotype effect: ${ }^{\delta} p<0.05$. FC/ Ext effect: ${ }^{+} p<0.05,{ }^{++} p<0.01,{ }^{+++} p<0.001$. Post hoc comparisons: ${ }^{*} p<0.05,{ }^{* *} p<0.01,{ }^{* * *} p<0.001$. A two-way ANOVA was used for all statistical comparisons. 
positive neurons compared with their respective WT group, and fear extinction reduced the number of activated cells in TgNTRK3 mice, with no effect in WT animals (Fig. 4F; genotype $\times$ Ext interaction: $F_{(1,16)}=8.62, p=0.01$; Bonferroni post hoc test: WT-naive vs TgNTRK3naïve, $p=0.019 ; \operatorname{TgNTRK3-naive~vs~}$ TgNTRK3-Ext, $p=0.003$ ). In the mITC, no differences in the number of c-Fos cells were observed between genotypes in the naive condition. However, fear extinction training, again, reduced the number of activated cells in TgNTRK3 but not in WT controls (Fig. 4F; genotype $\times$ Ext interaction: $F_{(1,16)}=13.82, p=0.002$; Bonferroni post hoc test: WT-naive vs TgNTRK3-naïve, $p=0.097$; TgNTRK3-naive vs TgNTRK3Ext, $p=1.8 \mathrm{E}-04$; WT-Ext vs TgNTRK3-Ext, $p=0.003)$. Extinction training activated the mPFC region of WT but not TgNTRK3 mice, with a significant genotype $\times$ Ext interaction found in both the PL and IL areas (Fig. $4 A, G$; PL: $F_{(1,16)}=4.1, p=0.061$; IL: $\left.F_{(1,16)}=8.6, p=0.01\right)$. Post hoc comparisons revealed that fear extinction increased the number of c-Fos-positive cells in PL region only in WT animals (WTnaive vs WT-Ext, $p=0.014$ ). In IL, the number of c-Fos-positive cells was higher in the WT-Ext group than in WT-naive or TgNTRK3-Ext group (WT-naive vs WTExt, $p=0.014$; WT-Ext vs TgNTRK3-Ext, $p=0.014)$.

In summary, fear extinction training does not activate mPFC in TgNTRK3 leading to the reduced inhibition of amygdala, as shown by higher neuronal activation of CeM nucleus. The higher neuronal activation observed in the CAlpy layer of ventral hippocampus of TgNTRK3 mice would contribute to the increased context fear.

To determine the exact nature of the activated cells found in the ventral hippocampus region, c-Fos staining in Thyl-YFP: NTRK3 double-transgenic mice allowed the visualization of activated pyramidal neurons. Thy1-YFP:NTRK3 mice have similar numbers of Thy1-YFP cells as Thy1-YFP:WT littermates (data not shown). However, we found a higher number of c-Fos/Thy1YFP double-positive cells in Thyl-YFP:NTRK3 mice compared with Thyl-YFP:WT mice in the ventral hippocampus CAlpy layer $\left(t_{(8)}=-2.9, p=0.0186\right)$, but not in CA3py layer $\left(t_{(8)}=\right.$ $-1.3, p=0.23$ ), after fear conditioning (Fig. $5 A, B$ ). Thus, the enhanced CA1 activation detected in c-Fos experiments corresponds with a higher number of activated pyramidal excitatory cells in ventral hippocampus CA1py layer of TgNTRK3 mice, possibly resulting in higher excitability of this region.

\section{Hippocampal overexcitability is due to an increased glutamatergic load}

Western blot analysis in total hippocampus extracts showed higher protein levels of VGLUT1 (Fig. $6 A ; t_{(8.3)}=-2.9, p=$ 0.018 ) and lower levels of GAD65/67 (Fig. $6 B ; t_{(16)}=2.3, p=$ 0.038 ) in TgNTRK3 mice, indicating an overall dysbalance toward excitation.
To further confirm and additionally map the glutamatergic/ GABAergic dysbalance, immunofluorescence staining against VGLUT1 and VGAT presynaptic markers was performed and analyzed in the stratum radiatum layers of CA1 and CA3 hippocampal regions, a subfield where pyramidal neurons receive their presynaptic inputs. Double immunofluorescence for VGLUT1 and VGAT (Fig. 6C) showed a significant increase in the VGLUT1/VGAT puncta ratio in CA1 srad (Fig. $6 D ; t_{(14)}=$ $-2.6, p=0.020)$, but not in CA3srad $\left(t_{(14)}=-0.8, p=0.453\right)$ of ventral hippocampus of TgNTRK3 mice. No differences were found in the size of the VGLUT1 and VGAT puncta in CA1 and CA3 (data not shown) or in the number of VGLUT1/PSD-95 puncta (excitatory synaptic contacts; Fig. $6 E$; CA1: $t_{(14)}=0.1, p=$ 0.92; CA3: $\left.t_{(14)}=0.06, p=0.95\right)$. Again, differences were detected only in the ventral hippocampus, but not in the dorsal hippocampus (data not shown).

Tiagabine, but not ifenprodil, administration rescues the fear phenotype in TgNTRK3 mice

We attempt to rescue the observed hippocampal phenotype by injecting ifenprodil or tiagabine immediately after contextual fear-conditioning training. Peripheral administration of an active ifenprodil dose (inducing hypolocomotion in both genotypes; data not shown) had no effect in contextual fear memory of WT and TgNTRK3 mice, at $24 \mathrm{~h}$ (Fig. 7A; treatment effect: 
A

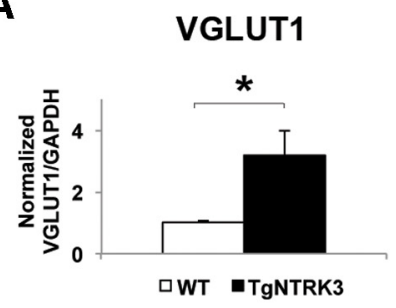

B

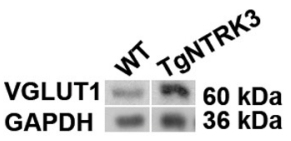

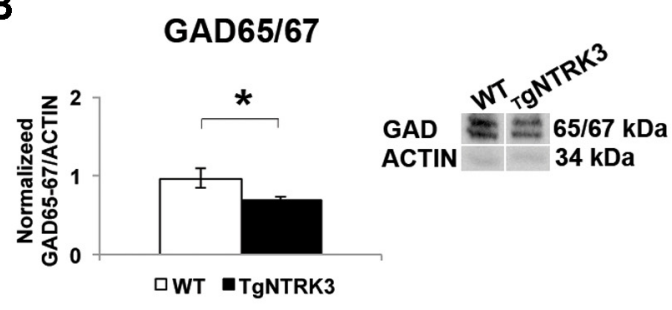

C
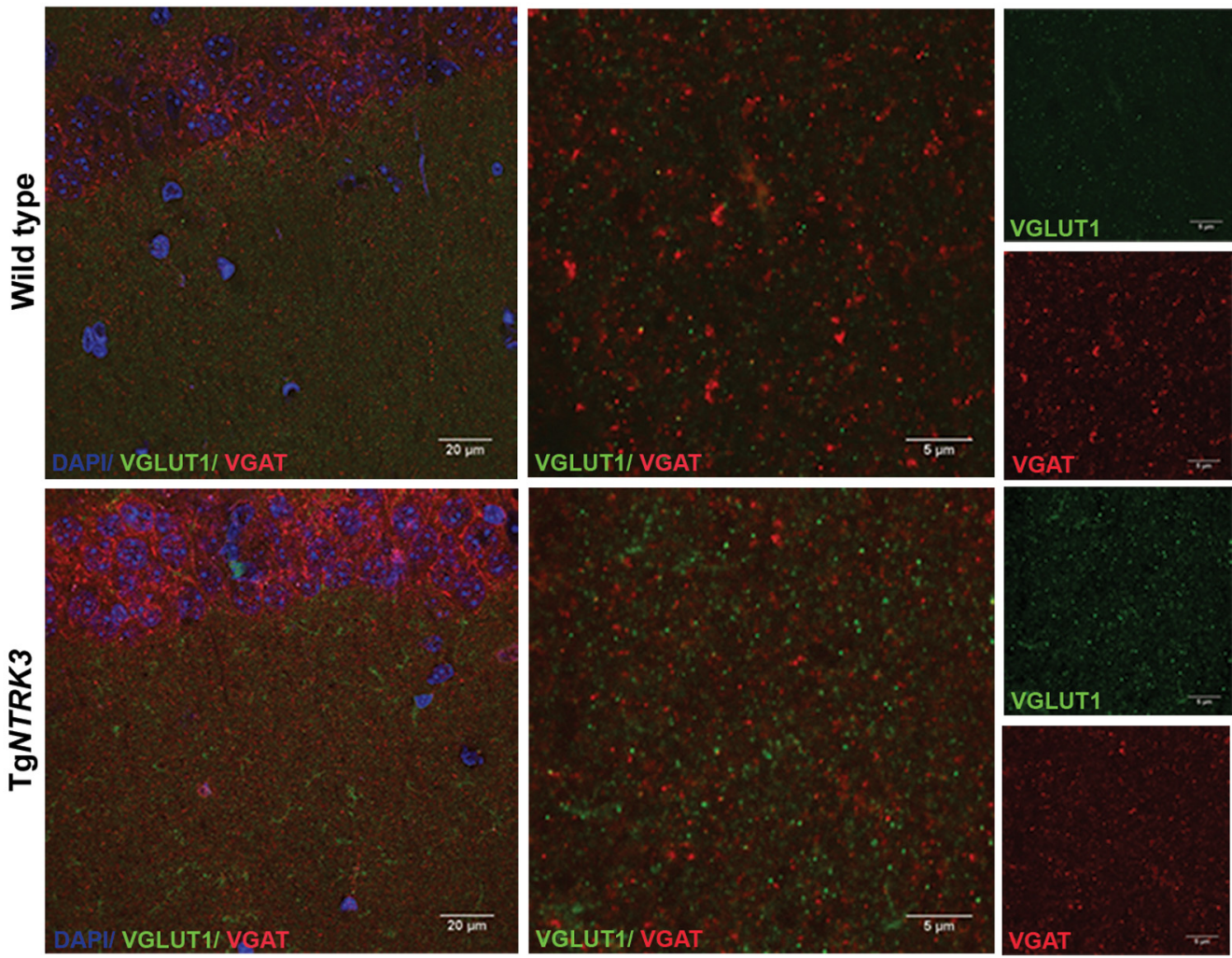

D

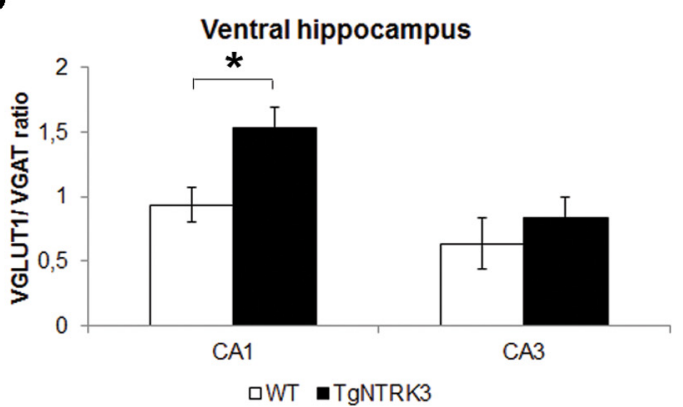

E

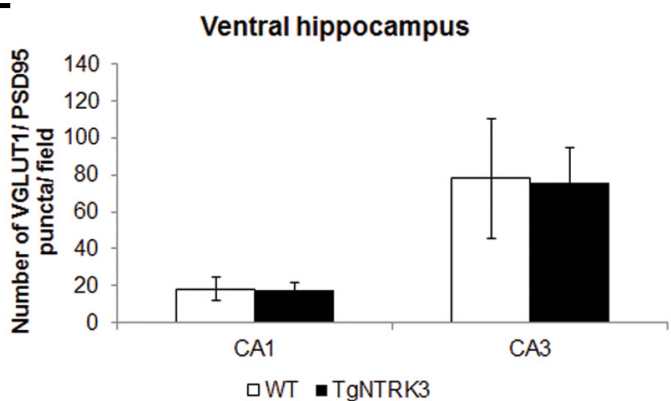

Figure 6. Excitatory-to-inhibitory dysbalance toward hyperexcitability in TgNTRK3 mice ventral hippocampus CA1 region. $\boldsymbol{A}$, $\boldsymbol{B}$, Western blot analysis of hippocampal extracts showed that

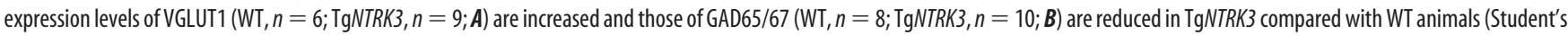
$t$ test). C, Representative photomicrographs of VGLUT1 and VGAT puncta immunofluorescence in ventral hippocampus CA1srad layer in WT and TgNTRK3 mice. D, Quantitative analyses of VGLUT1 and VGAT puncta in CA1srad and CA3srad showed a remarkable increase in VGLUT1/VGAT ratio in TgNTRK3 CA1srad layer with respect to WT (Student's $t$ test: WT, $n=5 ;$;gNTRK3, $n=6$ ). $E$, No differences were found between genotypes (Student's $t$ test: $n=8$ per genotype) when the number of excitatory (VGLUT1/PSD-95-positive) contacts were analyzed. GAPDH, glyceraldehyde-3phosphate dehydrogenase; Student's $t$ test: ${ }^{*} p<0.05$.

$F_{(1,36)}=0.8, p=0.38$; genotype effect: $F_{(1,36)}=5.7, p=0.023$; genotype $\times$ treatment effect: $\left.F_{(1,36)}=0.03, p=0.87\right)$.

However, peripheral tiagabine (GABA reuptake inhibitor) yielded a significant genotype $\times$ treatment interaction (Fig. $7 B$; $\left.F_{(1,30)}=12.2, p=0.0015\right)$. Post hoc comparisons showed that tiagabine decreased contextual fear memory in $\operatorname{TgNTRK} 3$ mice to
WT levels, with no effect in WT mice (TgNTRK3-saline vs TgNTRK3-tiagabine, $p=6.9 \mathrm{E}-06$; WT-saline vs TgNTRK3saline, $p=0.010$; WT-tiagabine vs TgNTRK3-tiagabine, $p=$ $0.036)$. Interestingly, when tiagabine was administered locally into the ventral hippocampus through implanted cannulae (Fig. 7C), both WT and TgNTRK3 mice showed a significant reduc- 
A

Ifenprodil i.p.

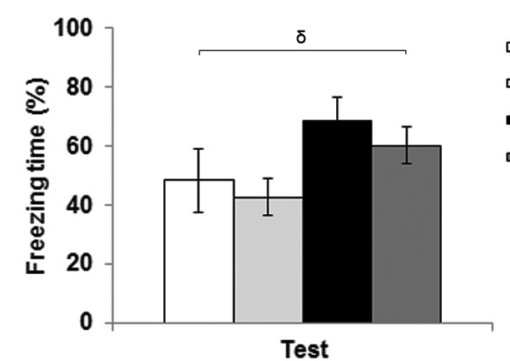

B

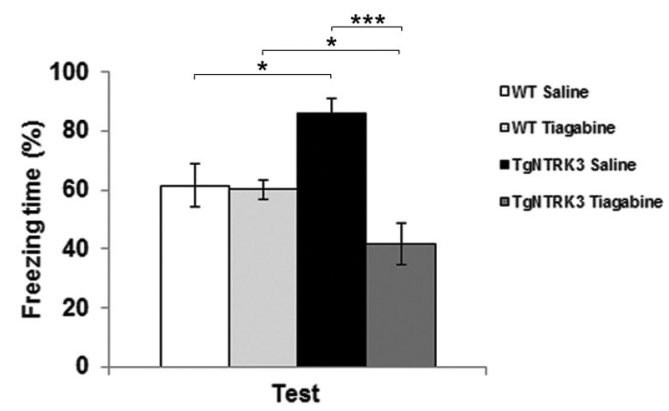

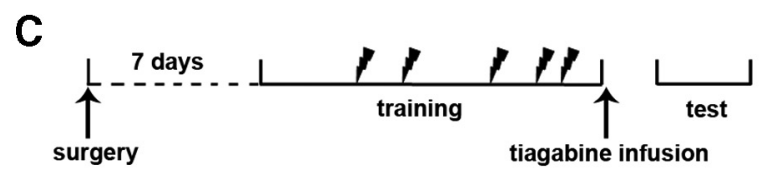

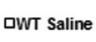
aWT Ifenprodil -TgNTRK3 Saline 口TgNTRK3 Ifenprodil
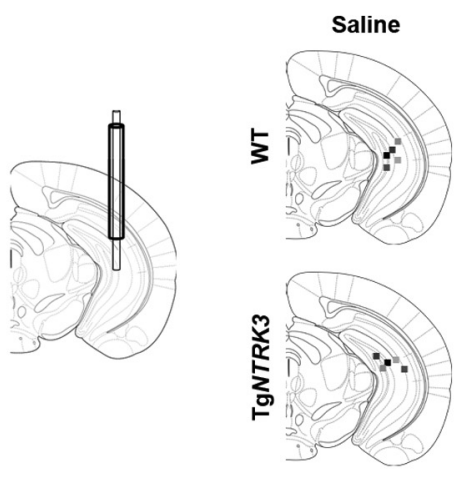
tiagabine

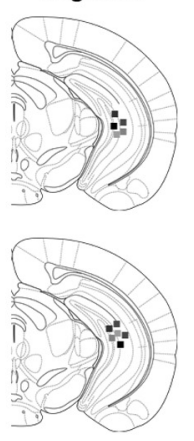

D

Tiagabine intra-hippocampal

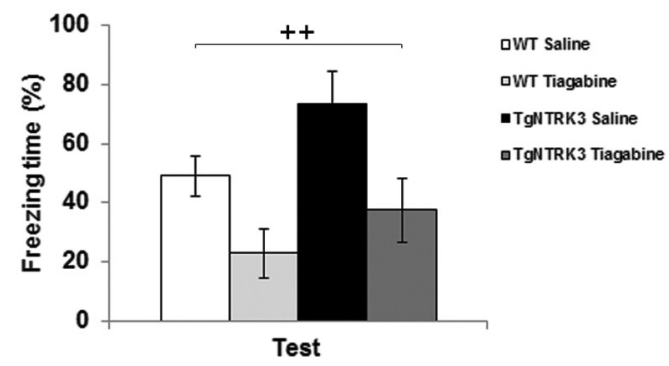

Figure 7. Increased fear memory in TgNTRK3 mice is normalized upon localized hippocampus GABA transmission enhancement. $\boldsymbol{A}, \boldsymbol{B}$, WT and TgNTRK3 mice were submitted to the pure contextual $\mathrm{FC}$ paradigm and immediately after the training session received intraperitoneal injection with saline, $1 \mathrm{mg} / \mathrm{kg}$ ifenprodil or $10 \mathrm{mg} / \mathrm{kg}$ tiagabine. Mice were tested for pure contextual fear memory $24 \mathrm{~h}$ after drug administration, and data showed that ifenprodil has no effect on fear memory in both WT and TgNTRK3 animals (two-way ANOVA: WT-saline, $n=9 ;$ WT-ifenprodil, $n=$ 10; TgNTRK3-saline, $n=10 ;$ TgNTRK3-ifenprodil, $n=11 ; \boldsymbol{A}$ ) and that tiagabine administration reduced the freezing time of TgNTRK3 mice and rescue contextual fear memory to WT levels ( $\boldsymbol{B}$ ), with no effect in WT mice (two-way ANOVA: WT-saline, $n=7$; WT-tiagabine, $n=8$; TgNTRK3-saline, $n=9$; TgNTRK3-tiagabine, $n=10$ ). C, Bilateral injection cannulae were implanted by stereotaxic surgery in the ventral hippocampus (following coordinates from Paxinos and Franklin, 2001) of WT and TgNTRK3 mice. After recovery from surgery, mice were submitted to the pure contextual fear conditioning and immediately after training infused with saline or $1 \mu \mathrm{g} /$ side of tiagabine. Schematic brain sections show the injection target site in the ventral hippocampus and the real infusion point in each mouse. $\boldsymbol{D}$, Twenty-four hours after tiagabine infusion, mice were tested for contextual fear memory. Quantification of freezing time shows that tiagabine infusion reduced fear response in both genotypes, compared with saline-infused groups (two-way ANOVA: WT-saline, $n=5$; WT-tiagabine, $n=5$; TgNTRK3-saline, $n=5 ;$ TgNTRK3-tiagabine, $n=6$ ). Genotype effect: ${ }^{\delta} p<$ 0.05. Treatment effect: ${ }^{++} p<0.01$. Post hoc comparisons: ${ }^{*} p<0.05,{ }^{* * *} p<0.001$.

tion of freezing response at the test phase (Fig. $7 D$; treatment effect: $\left.F_{(1,17)}=10.3, p=0.005\right)$ and a trend for a significant enhanced fear response in TgNTRK3 mice compared with WT (genotype effect: $\left.F_{(1,17)}=4.0, p=0.061\right)$. Thus, the increased contextual fear memory phenotype observed in TgNTRK3 mice is rescued by specifically strengthening GABAergic transmission in the ventral hippocampus, during the consolidation phase of fear memory.

\section{Discussion}

We here show an increased and resistant-to-extinction contextual fear memory in TgNTRK3 mice, a validated model of PAND. This phenotype can be explained by the abnormal activation of the amygdala-hippocampus-medial prefrontal cortex fear network and sustained hyperexcitability of CAlpy layer of ventral hippocampus, as supported by the rescue of contextual fear through administration of tiagabine, a GABA reuptake inhibitor. These results shed light on the mechanisms of the increased conditionability and resistance to extinction observed in PAND patients.
First, we found that training TgNTRK3 mice in hippocampaldependent fear-conditioning paradigms resulted in lastingly higher fear memory compared with WT controls (Fig. $1 A-F)$. In addition to the persistence of such enhanced fear memory, deficits in fear extinction are typical for anxiety disorders, such as post-traumatic stress disorder and PAND (American Psychiatric Association, 2000; Blechert et al., 2007; Michael et al., 2007). When submitted to a within-session paradigm, $\operatorname{TgNTRK} 3$ mice showed impaired fear extinction acquisition and memory (Fig. $1 G, H)$, but in the between-session paradigm we found no differences between genotypes (Fig. 1I). The presence of a consolidation phase after the presentation of each nonpaired CS, as is the case in the between-session paradigm, should contribute to the differences observed between the extinction paradigms. Strikingly, a similar dissociation of within-session and betweensession extinction has previously been reported for the mGLUR7 agonist AMN082, which impaired the former, but facilitated retention of the latter (Toth et al., 2012). Activation of mGLUR7 induces phosphorylation changes of MAPK signaling pathways 
(Tian et al., 2010), converging with TrkC-mediated signaling. The differences found between the two extinction paradigms may have implications for PAND clinical outcome when considering cognitive behavioral therapy in panic or other anxiety disorders. When TgNTRK3 mice were tested for contextual generalization (Fig. $1 H$ ), although we did not see a statistical significant difference in freezing levels, compared with WT, TgNTRK3 mice freeze more. We can speculate that transgenic animals are starting to develop a generalization of contextual fear response, a well described endophenotype in panic disorder that has been related to pattern separation and adult hippocampal neurogenesis (for review, see Kheirbek et al., 2012).

Interestingly, c-Fos expression was induced in pyramidal cells of ventral hippocampal area CA1 of both genotypes after fear conditioning, but to a much higher extent in TgNTRK3 animals (Figs. $4 A, B, 5 A, B$ ). Despite this increased hippocampal activity, TgNTRK3 mice showed mild impairments in another hippocampus-dependent memory test, the Morris water maze (MWM; Fig. 2), and no apparent deficits in the novel object recognition test (Fig. 3), suggesting a differential and complex effect of TrkC on hippocampal memory function. Fear conditioning and MWM tasks do rely on the hippocampus but are ascribed to different hippocampal subcircuits. While fear conditioning is mainly dependent on the ventral hippocampus, the MWM depends mainly on the dorsal hippocampus (Zhang et al., 2004). In fact, most of the histochemical differences we found were specific to the ventral hippocampus, with the dorsal hippocampus showing only subtle differences or no differences at all (data not shown).

Our results suggest that fear memories in TgNTRK3 mice could be modulated by recruiting different neural circuits. We studied the neural activation pattern of the amygdala, the hippocampus, and the $\mathrm{MPFC}$, which are critically involved in fear behavior. Naive TgNTRK3 mice showed increased c-Fos labeling in the CeM of the amygdala (Fig. $4 C, F$ ), which orchestrates conditioned autonomic and motor responses (LeDoux et al., 1988) as well as innate fear (Nanda et al., 2008). The basal overactivation of this region may thus explain the increased innate fear response of $\operatorname{TgNTRK} 3$ mice that was observed previously (Dierssen et al., 2006). Ventral hippocampal and mPFC inputs mostly impinge on LA/BLA and ITC of the amygdala to regulate fear (SierraMercado et al., 2011; Bienvenu et al., 2012). In our study, fearconditioning and extinction processes resulted in an important hypoactivation of the ITCs in TgNTRK3 mice, without affecting LA/BA activation pattern, suggesting that the disrupted fear may result from an impaired processing of incoming information into the ITCs. The fact that no differences are observed at the LA/BLA might suggest the occurrence of compensatory mechanisms at these nuclei. Upon contextual fear-conditioning training, c-Fos expression increased more strongly in CeM amygdala of TgNTRK3 mice (Fig. 4C), which is in line with their increased freezing response (Fig. $1 B, E$ ). In contrast, in the IL region of mPFC, fear-conditioning training led to an inhibition of c-Fos expression in TgNTRK3 but not in WT mice (Fig. 4D). These results indicate that fear-related information is processed by distinct spatial patterns of neuronal activity in the fear network in PAND, in which increased activation of ventral hippocampus and inhibition of mPFC during fear conditioning, converge with a hyper-reactive CeM, thus amplifying the fear signal. Importantly, the over-reactivity of both the ventral hippocampus and the CeM were resistant to extinction training in $\operatorname{TgNTRK} 3$ animals (Fig. 4E,F). Moreover, the mPFC (PL and IL regions), which is involved in the extinction of conditioned fear (Morgan et al., 1993; Quirk et al., 2000, 2003; Berretta et al., 2005), was not activated upon fear extinction in $\operatorname{Tg} N T R K 3$ mice (Fig. $4 G$ ). Inactivation of the IL region impairs the acquisition of fear extinction and extinction memory (Milad and Quirk, 2002; Sierra-Mercado et al., 2011), while the hippocampus is required for both fear expression and extinction memory, serving to disambiguate conflicting CS memories and determine performance (Holt and Maren, 1999; Corcoran and Maren, 2001; Corcoran et al., 2005; Sierra-Mercado et al., 2011). Accordingly, extinction of conditioned fear correlates with decreased c-Fos expression in the CeA and increased c-Fos expression in the IL cortex at extinction recall (Santini et al., 2004; Hefner et al., 2008). Thus, the increased and persistent c-Fos expression in the hippocampus and amygdala of TgNTRK3 mice identifies an abnormally active circuit that is likely causal for the observed changes in the fear responding of these animals.

Given the engagement of hippocampus in PAND (Charney, 2003; Massana et al., 2003a,b) and our results, the next experiments focused in this brain region. In the hippocampus, the glutamatergic and GABAergic neurotransmitter systems allow for dynamic and activity-dependent plastic functions, which are required for fear learning and memory processes. Strikingly, the analysis of excitatory (VGLUT1) and inhibitory (GAD65/67 and VGAT) neuronal markers suggests an imbalance in hippocampus of TgNTRK3 mice favoring hyperexcitability (Fig. 6A,B). In agreement with our observations of c-Fos induction, these changes mapped specifically to ventral CA1 hippocampal region (Fig. 6C,D). Interestingly, NT3 increases the probability of neurotransmitter release at the presynaptic terminal and promotes the establishment of functional excitatory synapses (Collin et al., 2001). However, no change was found in the number of excitatory synapses (VGLUT1/PSD-95) of TgNTRK3 animals (Fig. $6 E$ ), suggesting that changes in the efficacy of synaptic transmission and/or intracellular signaling may cause the altered learningrelated activation of this region. In fact, in TgNTRK3 mice NMDA receptor expression and LTP in the hippocampus are increased (Sahún et al., 2007). Despite the increase in hippocampal NR2B expression, the NR2B antagonist ifenprodil did not improve contextual memory deficits in TgNTRK3 mice (Fig. 7A).

In fact, in a behavioral model of panic/fear, periaqueductal gray stimulation induces long-lasting fear-like response by deactivation of the GABAergic system (parvalbumin-positive interneurons) in the hippocampus (Temel et al., 2012), suggesting that the inhibitory system is actively involved in the fear process. Thrillingly, increasing inhibition through administration of tiagabine, both systemically and more importantly locally in the hippocampus, rescued the contextual fear memory phenotype of TgNTRK3 mice (Fig. 7B). This is interesting in light of findings that tiagabine treatment improves panic or agoraphobic symptoms in PAND patients (Zwanzger and Rupprecht, 2005). Additionally, these results highlight the importance of a proper hippocampal functioning, supporting our hypothesis of the differential involvement of this structure in PAND.

We here provide strong evidence that the hippocampus has a critical role in PAND, a brain region in which TrkC is highly expressed. The recovery of fear memory by tiagabine administered locally in the hippocampus, demonstrates the crucial role of this brain structure in the effectiveness of pharmacological intervention. These results open a new avenue of investigation of the neural mechanisms underlying PAND pathogenesis, leading to better understanding of the pathophysiology of this disorder and to the identification of new putative therapeutic entries. The con- 
tribution of the neurotrophin receptor TrkC is probably extended to a broad range of anxiety disorders for which NTRK3 susceptibility has been found.

\section{References}

Alonso P, Gratacòs M, Menchón JM, Segalàs C, González JR, Labad J, Bayés M, Real E, de Cid R, Pertusa A, Escaramís G, Vallejo J, Estivill X (2008) Genetic susceptibility to obsessive-compulsive hoarding: the contribution of neurotrophic tyrosine kinase receptor type 3 gene. Genes Brain Behav 7:778-785. CrossRef Medline

American Psychiatric Association (2000) Diagnostic and statistical manual of mental disorders, Ed 4. Washington, DC: American Psychiatric Association.

Armengol L, Gratacòs M, Pujana MA, Ribasés M, Martín-Santos R, Estivill X (2002) 5' UTR-region SNP in the NTRK3 gene is associated with panic disorder. Mol Psychiatry 7:928-930. CrossRef Medline

Bangasser DA, Waxler DE, Santollo J, Shors TJ (2006) Trace conditioning and the hippocampus: the importance of contiguity. J Neurosci 26: 8702-8706. CrossRef Medline

Berretta S, Pantazopoulos H, Caldera M, Pantazopoulos P, Paré D (2005) Infralimbic cortex activation increases c-Fos expression in intercalated neurons of the amygdala. Neuroscience 132:943-953. CrossRef Medline

Bienvenu TC, Busti D, Magill PJ, Ferraguti F, Capogna M (2012) Cell-typespecific recruitment of amygdala interneurons to hippocampal theta rhythm and noxious stimuli in vivo. Neuron 74:1059-1074. CrossRef Medline

Blechert J, Michael T, Vriends N, Margraf J, Wilhelm FH (2007) Fear conditioning in posttraumatic stress disorder: evidence for delayed extinction of autonomic, experiential, and behavioural responses. Behaviour research and therapy 45:2019-2033. CrossRef Medline

Charney DS (2003) Neuroanatomical circuits modulating fear and anxiety behaviors. Acta Psychiatr Scand Suppl 38-50. Medline

Collin C, Vicario-Abejon C, Rubio ME, Wenthold RJ, McKay RD, Segal M (2001) Neurotrophins act at presynaptic terminals to activate synapses among cultured hippocampal neurons. Eur J Neurosci 13:12731282. CrossRef Medline

Corcoran KA, Maren S (2001) Hippocampal inactivation disrupts contextual retrieval of fear memory after extinction. J Neurosci 21:1720-1726. Medline

Corcoran KA, Desmond TJ, Frey KA, Maren S (2005) Hippocampal inactivation disrupts the acquisition and contextual encoding of fear extinction. J Neurosci 25:8978-8987. CrossRef Medline

Dierssen M, Gratacòs M, Sahún I, Martín M, Gallego X, Amador-Arjona A, Martínez de Lagrán M, Murtra P, Martí E, Pujana MA, Ferrer I, Dalfó E, Martínez-Cué C, Flórez J, Torres-Peraza JF, Alberch J, Maldonado R, Fillat C, Estivill X (2006) Transgenic mice overexpressing the full-length neurotrophin receptor TrkC exhibit increased catecholaminergic neuron density in specific brain areas and increased anxiety-like behavior and panic reaction. Neurobiol Dis 24:403-418. CrossRef Medline

Ernfors P, Merlio JP, Persson H (1992) Cells expressing mRNA for neurotrophins and their receptors during embryonic rat development. Eur J Neurosci 4:1140-1158. CrossRef Medline

Feng G, Mellor RH, Bernstein M, Keller-Peck C, Nguyen QT, Wallace M, Nerbonne JM, Lichtman JW, Sanes JR (2000) Imaging neuronal subsets in transgenic mice expressing multiple spectral variants of GFP. Neuron 28:41-51. CrossRef Medline

Goodwin RD, Faravelli C, Rosi S, Cosci F, Truglia E, de Graaf R, Wittchen HU (2005) The epidemiology of panic disorder and agoraphobia in Europe. Eur Neuropsychopharmacol 15:435-443. CrossRef Medline

Gratacòs M, Nadal M, Martín-Santos R, Pujana MA, Gago J, Peral B, Armengol L, Ponsa I, Miró R, Bulbena A, Estivill X (2001) A polymorphic genomic duplication on human chromosome 15 is a susceptibility factor for panic and phobic disorders. Cell 106:367-379. CrossRef Medline

Hefner K, Whittle N, Juhasz J, Norcross M, Karlsson RM, Saksida LM, Bussey TJ, Singewald N, Holmes A (2008) Impaired fear extinction learning and cortico-amygdala circuit abnormalities in a common genetic mouse strain. J Neurosci 28:8074-8085. CrossRef Medline

Herry C, Ciocchi S, Senn V, Demmou L, Müller C, Lüthi A (2008) Switching on and off fear by distinct neuronal circuits. Nature 454:600-606. CrossRef Medline

Holt W, Maren S (1999) Muscimol inactivation of the dorsal hippocampus impairs contextual retrieval of fear memory. J Neurosci 19:9054-9062. Medline

Hong CJ, Liou YJ, Tsai SJ (2011) Effects of BDNF polymorphisms on brain function and behavior in health and disease. Brain Res Bull 86:287-297. CrossRef Medline

Huang EJ, Reichardt LF (2001) Neurotrophins: roles in neuronal development and function. Annu Rev Neurosci 24:677-736. CrossRef Medline

Kessler RC, Chiu WT, Jin R, Ruscio AM, Shear K, Walters EE (2006) The epidemiology of panic attacks, panic disorder, and agoraphobia in the National Comorbidity Survey Replication. Arch Gen Psychiatry 63:415424. CrossRef Medline

Kheirbek MA, Klemenhagen KC, Sahay A, Hen R (2012) Neurogenesis and generalization: a new approach to stratify and treat anxiety disorders. Nat Neurosci 15:1613-1620. CrossRef Medline

Krause S, Schindowski K, Zechel S, von Bohlen und Halbach O (2008) Expression of trkB and trkC receptors and their ligands brain-derived neurotrophic factor and neurotrophin-3 in the murine amygdala. J Neurosci Res 86:411-421. CrossRef Medline

LeDoux JE, Iwata J, Cicchetti P, Reis DJ (1988) Different projections of the central amygdaloid nucleus mediate autonomic and behavioral correlates of conditioned fear. J Neurosci 8:2517-2529. Medline

Maren S, Quirk GJ (2004) Neuronal signalling of fear memory. Nat Rev Neurosci 5:844-852. CrossRef Medline

Massana G, Serra-Grabulosa JM, Salgado-Pineda P, Gastó C, Junqué C, Massana J, Mercader JM (2003a) Parahippocampal gray matter density in panic disorder: a voxel-based morphometric study. Am J Psychiatry 160: 566-568. CrossRef Medline

Massana G, Serra-Grabulosa JM, Salgado-Pineda P, Gastó C, Junqué C, Massana J, Mercader JM, Gómez B, Tobeña A, Salamero M (2003b) Amygdalar atrophy in panic disorder patients detected by volumetric magnetic resonance imaging. Neuroimage 19:80-90. CrossRef Medline

McAllister AK, Katz LC, Lo DC (1999) Neurotrophins and synaptic plasticity. Annu Rev Neurosci 22:295-318. CrossRef Medline

Michael T, Blechert J, Vriends N, Margraf J, Wilhelm FH (2007) Fear conditioning in panic disorder: enhanced resistance to extinction. J Abnorm Psychol 116:612-617. CrossRef Medline

Milad MR, Quirk GJ (2002) Neurons in medial prefrontal cortex signal memory for fear extinction. Nature 420:70-74. CrossRef Medline

Minichiello L, Korte M, Wolfer D, Kühn R, Unsicker K, Cestari V, RossiArnaud C, Lipp HP, Bonhoeffer T, Klein R (1999) Essential role for TrkB receptors in hippocampus-mediated learning. Neuron 24:401414. CrossRef Medline

Morgan MA, Romanski LM, LeDoux JE (1993) Extinction of emotional learning: contribution of medial prefrontal cortex. Neurosci Lett 163: 109-113. CrossRef Medline

Muiños-Gimeno M, Guidi M, Kagerbauer B, Martín-Santos R, Navinés R, Alonso P, Menchón JM, Gratacòs M, Estivill X, Espinosa-Parrilla Y (2009) Allele variants in functional MicroRNA target sites of the neurotrophin-3 receptor gene (NTRK3) as susceptibility factors for anxiety disorders. Hum Mutat 30:1062-1071. CrossRef Medline

Nanda SA, Qi C, Roseboom PH, Kalin NH (2008) Predator stress induces behavioral inhibition and amygdala somatostatin receptor 2 gene expression. Genes Brain Behav 7:639-648. CrossRef Medline

Otnaess MK, Djurovic S, Rimol LM, Kulle B, Kähler AK, Jönsson EG, Agartz I, Sundet K, Hall H, Timm S, Hansen T, Callicott JH, Melle I, Werge T, Andreassen OA (2009) Evidence for a possible association of neurotrophin receptor (NTRK-3) gene polymorphisms with hippocampal function and schizophrenia. Neurobiol Dis 34:518-524. CrossRef Medline

Paxinos G, Franklin K (2001) The mouse brain in stereotaxic coordinates. Amsterdam: Elsevier.

Quinn JJ, Ma QD, Tinsley MR, Koch C, Fanselow MS (2008) Inverse temporal contributions of the dorsal hippocampus and medial prefrontal cortex to the expression of long-term fear memories. Learn Mem 15:368 372. CrossRef Medline

Quirk GJ, Russo GK, Barron JL, Lebron K (2000) The role of ventromedial prefrontal cortex in the recovery of extinguished fear. J Neurosci 20:62256231. Medline

Quirk GJ, Likhtik E, Pelletier JG, Paré D (2003) Stimulation of medial prefrontal cortex decreases the responsiveness of central amygdala output neurons. J Neurosci 23:8800-8807. Medline

Roy-Byrne PP, Craske MG, Stein MB (2006) Panic disorder. Lancet 368: 1023-1032. CrossRef Medline 
Sahún I, Delgado-García JM, Amador-Arjona A, Giralt A, Alberch J, Dierssen M, Gruart A (2007) Dissociation between CA3-CA1 synaptic plasticity and associative learning in TgNTRK3 transgenic mice. J Neurosci 27: 2253-2260. CrossRef Medline

Santini E, Ge H, Ren K, Peña de Ortiz S, Quirk GJ (2004) Consolidation of fear extinction requires protein synthesis in the medial prefrontal cortex. J Neurosci 24:5704-5710. CrossRef Medline

Sierra-Mercado D, Padilla-Coreano N, Quirk GJ (2011) Dissociable roles of prelimbic and infralimbic cortices, ventral hippocampus, and basolateral amygdala in the expression and extinction of conditioned fear. Neuropsychopharmacology 36:529-538. CrossRef Medline

Skapinakis P, Lewis G, Davies S, Brugha T, Prince M, Singleton N (2011) Panic disorder and subthreshold panic in the UK general population: epidemiology, comorbidity and functional limitation. Eur Psychiatry 26:354-362. CrossRef Medline

Temel Y, Blokland A, Lim LW (2012) Deactivation of the parvalbuminpositive interneurons in the hippocampus after fear-like behaviour following electrical stimulation of the dorsolateral periaqueductal gray of rats. Behav Brain Res 233:322-325. CrossRef Medline
Tian Y, Liu Y, Chen X, Kang Q, Zhang J, Shi Q, Zhang H (2010) AMN082 promotes the proliferation and differentiation of neural progenitor cells with influence on phosphorylation of MAPK signaling pathways. Neurochemistry international 57:8-15. CrossRef Medline

Toth I, Dietz M, Peterlik D, Huber SE, Fendt M, Neumann ID, Flor PJ, Slattery DA (2012) Pharmacological interference with metabotropic glutamate receptor subtype 7 but not subtype 5 differentially affects within- and between-session extinction of Pavlovian conditioned fear. Neuropharmacology 62:1619-1626. CrossRef Medline

Vorhees CV, Williams MT (2006) Morris water maze: procedures for assessing spatial and related forms of learning and memory. Nat Protocols 1:848-858. CrossRef Medline

Zhang WN, Pothuizen HH, Feldon J, Rawlins JN (2004) Dissociation of function within the hippocampus: effects of dorsal, ventral and complete excitotoxic hippocampal lesions on spatial navigation. Neuroscience 127: 289-300. CrossRef Medline

Zwanzger P, Rupprecht R (2005) Selective GABAergic treatment for panic? Investigations in experimental panic induction and panic disorder. J Psychiatry Neurosci 30:167-175. Medline 